\title{
O USO DA CANNABIS MEDICINAL NO MANEJO DA DOR EM CUIDADOS PALIATIVOS: CONFLITOS E PERSPECTIVAS FUTURAS
}

Categoria: Clínico.

Instituição: Centro Universitário São Camilo (CUSC).

Autores: $\underline{\text { Pontes, } \mathrm{MF}^{1}}$; Gonçalves, $\mathrm{GS}^{1}$; Marques, $\mathrm{JS}^{1}$; Boza, AJB ${ }^{1}$; Santos, $\mathrm{AJA}^{1}$; Araujo, MTS ${ }^{2}$.

${ }^{1}$ Discente do Curso de Medicina do Centro Universitário São Camilo.

${ }^{2}$ Orientadora do artigo.

Endereço do autor principal: Rua Nossa Senhora da Saúde, 1322

Telefone do autor principal: (11) 976369101

E-mail do autor principal: milena.pontes31@,outlook.com 


\section{O USO DA CANNABIS MEDICINAL NO MANEJO DA DOR EM CUIDADOS PALIATIVOS: CONFLITOS E PERSPECTIVAS FUTURAS}

\section{Categoria: Clínico.}

Descritores: Dor, Cuidados Paliativos, Maconha Medicinal. 


\section{O USO DA CANNABIS MEDICINAL NO MANEJO DA DOR EM CUIDADOS PALIATIVOS: CONFLITOS E PERSPECTIVAS FUTURAS}

\section{RESUMO:}

INTRODUÇÃO: Os efeitos farmacológicos da planta Cannabis sativa L. são utilizados para diversas finalidades terapêuticas. Apesar de comprovadas, há grande dificuldade para a sua legalização em muitos países, como o Brasil. Entre os canabinóides, o $\Delta$-9-tetrahidrocanabinol e canabidiol são os mais ativos clinicamente e por meio do receptor CB1, suprime a excitabilidade neuronal. Os cuidados paliativos (CP) buscam tratamentos que aliviem o sofrimento psicossocial, espiritual e físico, como a dor, através das propriedades da Cannabis medicinal.

OBJETIVOS: Revisar as evidências clínicas publicadas em artigos científicos sobre o uso da Cannabis medicinal no manejo da dor em pacientes sob CP.

METODOLOGIA: Foi realizada uma revisão bibliográfica na base de dados PubMed, com os descritores DeCS: Pain, Palliative Care e Medical Marijuana, e o operador booleano AND. Foram encontrados 18 artigos e aplicados os critérios de exclusão: revisão, relato de caso e fuga do tema, e inclusão: língua portuguesa e inglesa, resultando em 4 artigos. Devido a escassez na literatura, resultados primários de revisões foram incluídos, totalizando 11 estudos.

RESULTADOS: Há controvérsias com relação ao uso da C. sativa L em CP. Registros de ensaios clínicos realizados, principalmente em oncologia, mostraram resultados promissores na redução da dor, porém efeitos colaterais foram observados, como: tontura, xerostomia, aumento do apetite e efeito psicoativo. Em conformidade, alguns autores pontuaram os benefícios da Cannabis medicinal em CP no tratamento da dor decorrente de esclerose múltipla e mieloma múltiplo, devido à redução da propagação de estímulos dolorosos, com alívio da dor, permitindo redução na dependência a opióides. Ainda, um estudo revelou que após o tratamento com óleo houve queda na dor em 48,3\% da amostra ( $\mathrm{p}<0,001)$. Outro, com pacientes com câncer, $70 \%$ relataram redução da dor após fumar a planta. Outros autores não recomendam o uso em pacientes idosos devido a dados insuficientes para determinar sua segurança. A Federação Europeia da Dor (EFIC) também aponta preocupações no uso da planta e na cobertura dos custos pelo seguro de saúde.

CONCLUSÃO: Apesar de evidências que apoiam o uso de Cannabis medicinal em CP, são necessários estudos maiores e esclarecimentos quanto à diferença entre a droga ilegal e o medicamento, de forma que é necessário capacitar profissionais e pacientes para superar os estigmas em torno do uso da planta.

DESCRITORES: Dor, Cuidados Paliativos, Maconha Medicinal. 


\section{O USO DA CANNABIS MEDICINAL NO MANEJO DA DOR EM CUIDADOS PALIATIVOS: CONFLITOS E PERSPECTIVAS FUTURAS}

\section{INTRODUÇÃO}

A Organização Mundial da Saúde (OMS) ${ }^{1}$ conceitua os Cuidados Paliativos como a "assistência promovida por uma equipe multidisciplinar, que objetiva a melhoria da qualidade de vida do paciente e seus familiares, diante de uma doença que ameace a vida, através da prevenção e alívio do sofrimento, por meio de identificação precoce, avaliação impecável e tratamento de dor e demais sintomas físicos, sociais, psicológicos e espirituais". Nesse ínterim, a dor, definida pela Associação Internacional para o Estudo da Dor (IASP) como "uma experiência sensitiva e emocional desagradável associada, ou semelhante àquelas associadas, a uma lesão tecidual real ou potencial" do paciente em cuidados paliativos deve ser aliviada.

Visando maneiras para esse controle, estuda-se as propriedades farmacológicas da Cannabis Medicinal.

Além da avaliação tradicional, na análise da dor em cuidados paliativos deve-se sempre buscar compreender como isso afeta o paciente não somente na esfera física, mas também no aspecto emocional, social e espiritual. ${ }^{3}$

A forma como cada paciente sente, conta e suporta a dor reflete em parte suas crenças pessoais e vivências anteriores. Assim, compreender as expectativas do paciente e também de seus familiares no tratamento da dor são de grande importância para estabelecimento de meta terapêutica. Baseado nisso, nos cuidados paliativos, o médico jamais poderá impor suas próprias crenças e julgamentos sobre o tratamento do paciente, já que nesse âmbito a vivência pessoal é de grande valor. ${ }^{3}$

Em cuidados paliativos é comum os pacientes em fase terminal não sentirem somente dor física, mas também não física e expressarem seus sofrimentos e angústias emocionais por meio de dor, devido principalmente a uma dificuldade de identificá-los e de buscar ajuda direcionada. Assim, as dores não físicas não podem ser aliviadas com medicamentos e, portanto, necessitam de uma abordagem multiprofissional que vai além do médico paliativista (psicólogo, assistente social, capelão, etc.). Quando não é dada a atenção necessária a esse aspecto da dor em cuidados paliativos, os pacientes podem não receber o alívio adequado e permanecerem em sofrimento. ${ }^{3}$

Em relação à temática estudada, o perfil principal dos pacientes eletivos para tratamento com Cannabis Medicinal no alívio da dor física em cuidados paliativos, são aqueles que possuem 
dores crônicas ${ }^{4,5}$, tais como dores relacionadas ao câncer em estágio avançado ${ }^{6}$, dor neuropática ${ }^{7}$, dor neuropática induzida por quimioterapia ${ }^{8}$ e dor $^{9}$ e espasticidade ${ }^{7}$ relacionada à esclerose múltipla.

Maida $^{10}$ descreve que a Cannabis Medicinal tem a intenção de aliviar sintomas, dentre eles a dor, como já citado anteriormente, diferentemente da Cannabis recreativa, que tem a intenção de gerar um estado psicomimético. E, quando usada para fins terapêuticos, pode ter sua composição alterada e adaptada para servir às necessidades individuais de cada paciente. A planta Cannabis sativa L. tem diversos efeitos, a depender dos seus princípios ativos. A partir dela é possível obter-se diversos canabinóides e entre eles os mais relevantes clinicamente são o delta-9-tetrahidrocanabinol (THC) e o canabidiol (CBD). Além destes, tem-se os elementos não canabinóides, terpenóides e flavonóides e observa-se sinergia entre os dois tipos. Em relação às vias de administração da Cannabis medicinal, a mesma pode ser dispensada de forma seca para ser fumada, vaporizada ou até ingerida por via oral, assim como os extratos feitos de óleo.

Os princípios ativos, então, agem através do sistema canabinóide endógeno, o qual é composto por receptores e seus agonistas. ${ }^{10}$

O Sistema Endocanabinóide: produção endógena de canabinóides como anandamida e 2-araquidonilglicerol (2-AG), que, apesar de não serem armazenados, são produzidos conforme necessidade, auxiliam na manutenção da homeostase ${ }^{12}$. Um exemplo de alteração da homeostase foi elucidado, uma vez que há evidências de que a sinalização endocanabinoide se altera em doenças neurodegenerativas parecendo provável que exerça algum grau de limite da progressão da doença ou sintomas ${ }^{12}$. Mas, para que exerçam efeito é necessário que os canabinóides se liguem a receptores que, por sua vez, podem ser encontrados no cérebro, fígado, pâncreas, tecido conjuntivo, ossos, tecido adiposo, sistema nervoso e imunológico. Dentre os diversos tipos existentes, destacam-se o receptor do tipo 1 (CB1) que é observado principalmente no cérebro e o tipo 2 (CB2) localizado predominantemente no sistema imunológico e nos ossos ${ }^{11}$.

Dentre os efeitos pontuados, no sistema nervoso foi observada importante regulação das atividades neuronais. Os endocanabinóides atuam como neuromoduladores. A regulação neural se dá pela ligação a receptores CB1 que estão localizados na membrana plasmática das terminações nervosas de forma que há a inibição da liberação de neurotransmissores pelas terminações pré-sinápticas por ações celulares de inibição da entrada de cálcio e hiperpolarização em função da ativação dos canais de potássio. A distribuição celular dos receptores CB1 e das enzimas sn-1-diacilglicerol lipase (DAGL) e monoacilglicerol lipase (MAGL) compatibilizam-se bem com a ideia de que o endocanabinoide 2-AG poderia ser um mensageiro "retrógrado" na supressão da inibição induzida por despolarização (DSI). A DSI pode ser bloqueada por um antagonista CB1, 
como o rimobananto. Ainda no SNC foram observados receptores CB2 presentes na micróglia (células imunológicas do SNC que quando ativadas contribuem para a dor crônica) ${ }^{12}$.

Visto isso, canabinóides exógenos, encontrados na planta Cannabis, ao se ligarem a esses receptores causam efeitos que podem ser utilizados para fins medicinais e que serão destacados ao decorrer desse estudo.

Dentre os canabinoides exógenos existentes, o tetrahidrocanabinol (THC), que se liga principalmente a receptores CB1 no cérebro destaca-se e tem efeito psicoativo, ao passo que no receptor $\mathrm{CB} 2$ o canabidiol (CBD) é o canabinoide exógeno de destaque, uma vez que atua principalmente no sistema imunológico, mas não causa o efeito psicoativo mencionado para o THC. Dada a relação entre receptores CB2 e o sistema imunológico, a ligação a receptores CB2 tem maior predomínio na carcinogênese do que nos receptores $\mathrm{CB} 1$, de forma que os canabinoides têm um impacto na migração, angiogênese, autofagia e/ou apoptose (morte celular programada) de células cancerosas, mas vale ressaltar que esses efeitos foram observados em estudos "in vitro" e que cada tipo de câncer responde de forma diferente aos canabinoides exógenos a depender da concentração de receptores CB1 ou CB2, de forma que são necessários mais estudos que elucidem esses efeitos. Contudo, de fato, a desregulação no sistema endocanabinoide pode promover proliferação de células cancerosas e canabinóides medicamentosos podem promover efeito anti-câncer em seres humanos ${ }^{11}$. Os canabinoides sintéticos são comumente pulverizados em material fitoterápico e fumados, mas também são usados na forma de cristal e pó e são agonistas do receptor canabinóide $\mathrm{CB} 1$, alvo por meio do qual o delta-tetra-hidrocanabinol (THC), principal ingrediente psicoativo da Cannabis exerce seus efeitos ${ }^{12}$.

A Cannabis é cada vez mais utilizada no tratamento paliativo de pacientes oncológicos pelos seus efeitos de alívio. Esses, dependem muito da forma de ingestão, forma sintética ou uso da planta, cepa da Cannabis utilizada e do próprio sistema endocanabinoide do paciente. Ainda sim, cada vez mais tem sido usada para analgesia, aumento de apetite, combate a anorexia e controle de náuseas e vômitos. Ainda em cuidados paliativos, outro uso apontado em estudos é o de efeito positivo no humor, o que ajuda o paciente na intenção de cura, e até mesmo melhora no sono e interações sociais, efeitos de suma importância e que estão em consonância com os princípios da medicina contemporânea, em que busca-se cuidar do paciente como um todo, através de uma visão holística, e não apenas a cura de uma doença ${ }^{11}$.

Além dos efeitos citados e investigados na atual conjuntura, salta aos olhos a segurança da Cannabis, visto que não há relatos na literatura de overdose ou morte por sua ingestão ${ }^{11}$. Não há 
depressão grave da função respiratória ou cardiovascular pela escassez de receptores CB1 no tronco encefálico $^{12}$.

A Cannabis medicinal age através do sistema endocanabinóide, bem descrito na literatura e explicado acima, assim como seus efeitos no corpo humano e possíveis usos terapêuticos. Porém, ainda há alguns impasses para sua utilização, tanto para certificar a segurança e eficácia da droga quanto sua legalização, inclusive no Brasil. Falar sobre a legalização da Cannabis para uso medicinal envolve não só a esfera política, mas também questões sociais, culturais e religiosas. Historicamente seu uso vem sendo debatido, principalmente em relação ao benefício que pode ser promovido às famílias e pacientes que possuem dor crônica. Ao passo que ocorre avanços na área da ciência e da saúde quanto sua eficácia, sua legalização continua restritiva. É proibido por lei o plantio, cultura, colheita, extração ou produção de substratos provenientes da Cannabis, com exceção de autorização legal. Assim, é ilegal o consumo de Cannabis, sendo o seu uso uma atividade criminosa punida por Lei. Porém, desde o início do século XXI ocorrem avanços nas pesquisas e estudos, motivados pelo interesse no conhecimento dos componentes da planta. Somente em 2017 a Agência Nacional de Vigilância Sanitária (ANVISA) aprovou a maconha como erva medicinal, registrando o primeiro medicamento à base de Cannabis no Brasil, cuja composição é o tetrahidrocanabinol e canabidiol. Ainda assim, vale ressaltar que essa medida não permite o uso medicinal da planta em qualquer situação, somente em situações terapêuticas específicas que exigem autorização. Portanto, a luta a favor do uso da Cannabis medicinal vem avançando e isso revela o quão necessário são mais estudos com dados clínicos significativos, comprovando seu potencial uso terapêutico ${ }^{15,16}$.

\section{OBJETIVOS}

Revisar as evidências clínicas publicadas em artigos científicos sobre o uso da Cannabis medicinal no manejo da dor em pacientes sob cuidados paliativos.

\section{METODOLOGIA}

Foi realizada uma revisão bibliográfica na base de dados PubMed, com os descritores DeCS: Pain, Palliative Care e Medical Marijuana, e o operador booleano AND. Foram encontrados 18 artigos e aplicados os critérios de exclusão: revisão, relato de caso e fuga do tema, e inclusão: língua portuguesa e inglesa, resultando em 4 artigos. Devido a escassez na literatura, resultados primários de revisões foram incluídos, totalizando 11 estudos (Figura 1). 


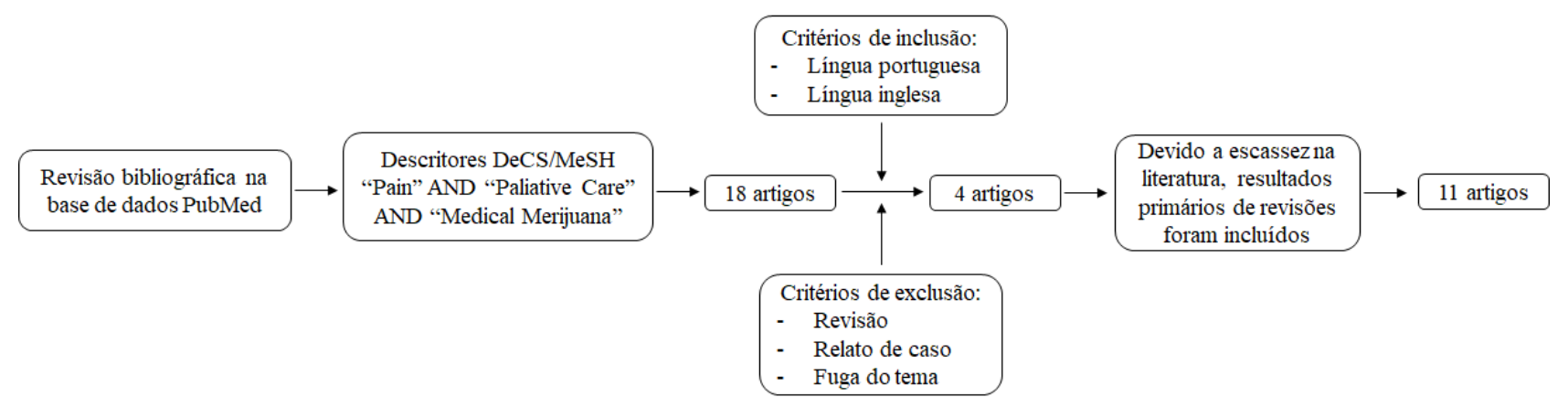

Figura 1: Fluxograma para seleção dos artigos científicos.

\section{RESULTADOS}

Nas tabelas a seguir estão resumidos os principais aspectos dos artigos selecionados. A tabela 1 sobre o uso da Cannabis em cuidados paliativos de pacientes com câncer. A tabela 2 discorre sobre o uso da Cannabis nos Cuidados Paliativos da esclerose múltipla. A tabela 3 relata o uso da Cannabis inserido no contexto de cuidados paliativos no mieloma múltiplo. Na tabela 4 relacionam-se os principais resultados sobre o uso da Cannabis nos cuidados paliativos de pacientes com dor crônica, dor e caquexia relacionada ao câncer, demência e doença de Alzheimer e doenças crônicas. E na tabela 5 encontra-se o resultado do artigo que comenta sobre questões legais do uso da Cannabis na Europa. 
Tabela 1: Resumo dos principais aspectos relacionados aos Cuidados Paliativos em oncologia e uso da Cannabis Medicinal

\begin{tabular}{|c|c|c|c|c|}
\hline Título & $\begin{array}{l}\text { Ano e } \\
\text { desenho de } \\
\text { estudo }\end{array}$ & Amostra & Objetivos & Resultados \\
\hline $\begin{array}{l}\text { Cannabis for } \\
\text { cancer - } \\
\text { illusion or the } \\
\text { tip of an } \\
\text { iceberg: a } \\
\text { review of the } \\
\text { evidence for } \\
\text { the use of } \\
\text { Cannabis and } \\
\text { synthetic } \\
\text { cannabinoids } \\
\text { in oncology. }\end{array}$ & $\begin{array}{l}\text { Revisão } \\
\text { integrativa, } \\
2019\end{array}$ & $\begin{array}{l}28 \text { Ensaios } \\
\text { clínicos } \\
\text { randomizados. }\end{array}$ & $\begin{array}{l}\text { Apresentar os } \\
\text { mecanismos de } \\
\text { ação, discutir as } \\
\text { formulações atuais } \\
\text { de canabinóides e } \\
\text { suas rotas de } \\
\text { administração. } \\
\text { Descrever os } \\
\text { efeitos adversos e } \\
\text { as barreiras e } \\
\text { limitações da } \\
\text { pesquisa da } \\
\text { Cannabis nos dias } \\
\text { atuais. }\end{array}$ & $\begin{array}{l}\text { Um dos estudos demonstrou que altas } \\
\text { doses de } \Delta 9 \text {-THC foram } \\
\text { significativamente superior ao placebo } \\
\text { na redução da dor e comparável à } \\
\text { codeína, no entanto, foram associados a } \\
\text { uma sedação considerável. Outro } \\
\text { estudo encontrou uma proporção maior } \\
\text { de pacientes relatando analgesia com } \\
\text { doses baixas e médias de nabiximol, do } \\
\text { que com placebo, enquanto a baixa } \\
\text { tolerabilidade ao medicamento foi } \\
\text { observada no grupo de alta dose. Da } \\
\text { mesma forma, outro estudo avaliou } \\
\text { sintomas relacionados ao câncer } \\
\text { relatados pelo paciente durante o uso } \\
\text { de Cannabis medicinal e descobriram } \\
\text { não apenas redução da dor, mas } \\
\text { também redução na dose de opióides } \\
\text { em quase metade dos indivíduos. }\end{array}$ \\
\hline
\end{tabular}

Medical Revisão da
Cannabis: $\quad$ Literatura,
The Oncology 2018.
Nurse's Role
in Patient
Education
About the
Effects of
Marijuana on
Cancer
Palliation.

Discutir o sistema $\mathrm{O}$ enfermeiro oncológico pode endocanabinóide

humano como desempenhar um papel fundamental no base para melhor apoio ao paciente que fizer uso de compreensão da Cannabis como medicamento paliativo e curativo, bem como revisar os métodos de entrega do medicamento ao paciente e o papel do enfermeiro oncológico nesse contexto. 


\begin{tabular}{|c|c|c|c|c|}
\hline Título & $\begin{array}{l}\text { Ano e } \\
\text { desenho de } \\
\text { estudo }\end{array}$ & Amostra & Objetivos & Resultados \\
\hline
\end{tabular}

\begin{tabular}{|c|c|c|c|}
\hline $\begin{array}{l}\text { Patterns of } \\
\text { use of } \\
\text { medical } \\
\text { cannabis } \\
\text { among Israeli } \\
\text { cancer } \\
\text { patients: a } \\
\text { single } \\
\text { institution }\end{array}$ & $\begin{array}{l}\text { Estudo } 279 \text { pacientes } \\
\text { Observacional, com câncer. } \\
2015 \text {. }\end{array}$ & $\begin{array}{l}\text { Verificar as } \\
\text { indicações e a } \\
\text { eficácia do uso de } \\
\text { Cannabis em } \\
\text { pacientes com } \\
\text { câncer. }\end{array}$ & $\begin{array}{l}\text { Dos } 17.000 \text { pacientes com câncer } \\
\text { atendidos, somente } 279 \text { receberam } \\
\text { autorização para a utilização da } \\
\text { Cannabis. Com o uso, foram relatados } \\
\text { melhora na dor }(70 \%) \text {, no bem-estar } \\
\text { geral }(70 \%) \text {, no apetite }(60 \%) \text { e nas } \\
\text { náuseas }(50 \%) \text {. Os efeitos colaterais } \\
\text { foram leves, principalmente fadiga e } \\
\text { tontura. }\end{array}$ \\
\hline
\end{tabular}

\begin{tabular}{|c|c|c|c|}
\hline $\begin{array}{l}\text { Prospective } \\
\text { analysis of } \\
\text { safety and } \\
\text { efficacy of } \\
\text { medical } \\
\text { cannabis in } \\
\text { large } \\
\text { unselected } \\
\text { population of } \\
\text { patients with }\end{array}$ & $\begin{array}{l}\text { Estudo } \\
\text { prospectivo, } \\
2018\end{array}$ & $\begin{array}{l}2.970 \text { pacientes } \\
\text { com câncer } \\
\text { tratados com } \\
\text { Cannabis } \\
\text { medicinal entre } \\
2015 \text { e } 2017 \text {. }\end{array}$ & $\begin{array}{l}\text { Caracterizar a } \\
\text { epidemiologia de } \\
\text { pacientes com } \\
\text { câncer recebendo } \\
\text { tratamento médico } \\
\text { com Cannabis e } \\
\text { descrever a } \\
\text { segurança e } \\
\text { eficácia desta } \\
\text { terapia. }\end{array}$ \\
\hline
\end{tabular}

Os principais sintomas que necessitaram de terapia: problemas de sono $(78,4 \%)$, dor $(77,7 \%)$, fraqueza $(72,7 \%)$, náuseas $(64,6 \%)$ e falta de apetite (48,9\%). De 1386 pacientes, $95,9 \%$ relataram uma melhora em sua condição, 3,7\% não relataram nenhuma mudança e $0,3 \%$ relataram piora em sua condição. Após 6 meses do tratamento, $50,8 \%$ dos pacientes reportaram uma melhora significativa; $45,1 \%$ melhora moderada ou leve e $4,0 \%$ não experimentaram um efeito positivo. Antes do início do tratamento, $52,9 \%$ dos pacientes relataram dor no intervalo de 8 a 10 , enquanto apenas $4,6 \%$ relataram esta intensidade após seis meses de tratamento ( $p<0,001)$. Apenas $18,7 \%$ dos pacientes relataram boa qualidade de vida antes do tratamento, enquanto $69,5 \%$ a relataram em 6 meses $(\mathrm{p}<0,001)$. Houve melhora nos sintomas: náuseas e vômitos $(91,0 \%)$, distúrbios do sono (87,5\%), inquietação (87,5\%), ansiedade e depressão $(84,2 \%)$, prurido $(82,1 \%)$ e cefaléia $(81,4 \%)$. Após o uso da Cannabis, $35,1 \%$ relataram diminuição no consumo de analgésicos e antipiréticos, hipnóticos e sedativos, corticosteróides e opióides. 


\begin{tabular}{|c|c|c|c|c|}
\hline Título & $\begin{array}{l}\text { Ano e } \\
\text { desenho de } \\
\text { estudo }\end{array}$ & Amostra & Objetivos & Resultados \\
\hline $\begin{array}{l}\text { Concerns of } \\
\text { patients with } \\
\text { cancer on } \\
\text { accessing } \\
\text { cannabis } \\
\text { products in a } \\
\text { state with } \\
\text { restrictive } \\
\text { medical } \\
\text { marijuana } \\
\text { laws: a } \\
\text { survey study. }\end{array}$ & Survey, 2019 & $\begin{array}{l}101 \text { pacientes } \\
\text { de uma clínica } \\
\text { acadêmica de } \\
\text { cuidados } \\
\text { paliativos } \\
\text { responderam } \\
\text { um questionário } \\
\text { acerca do uso } \\
\text { de Cannabis } \\
\text { medicinal. }\end{array}$ & $\begin{array}{l}\text { Analisar os meios } \\
\text { de obtenção, quais } \\
\text { os produtos } \\
\text { derivados da } \\
\text { Cannabis utilizados } \\
\text { e o acesso à } \\
\text { Cannabis. }\end{array}$ & $\begin{array}{l}\text { A utilização do óleo de THC no } \\
\text { câncer avançado foi de } 76 \% ; 15 \% \\
\text { indicaram o uso de óleo puro de } \\
\text { CBD; } 95 \% \text { dos pacientes afirmaram } \\
\text { que o uso de produtos derivados da } \\
\text { Cannabis é importante ou } \\
\text { extremamente importante na redução } \\
\text { da dor; os efeitos adversos foram } \\
\text { relatados como mínimos, porém o } \\
\text { mais citado pelos pacientes foi a } \\
\text { sedação (27\%); } 48 \% \text { dos pacientes } \\
\text { começaram a utilizar o produto por } \\
\text { recomendação médica. }\end{array}$ \\
\hline
\end{tabular}

Tabela 2: Principais aspectos relacionados aos Cuidados Paliativos na Esclerose múltipla do artigo.

\begin{tabular}{|c|c|c|c|c|}
\hline Título & $\begin{array}{l}\text { Ano e } \\
\text { desenho de } \\
\text { estudo }\end{array}$ & Amostra & Objetivos & Resultados \\
\hline $\begin{array}{l}\text { Preserving the } \\
\text { independence of } \\
\text { people living } \\
\text { with multiple } \\
\text { sclerosis } \\
\text { towards the end } \\
\text { of life. }\end{array}$ & $\begin{array}{l}\text { Revisão } \\
\text { Clínica com } \\
\text { relato de } \\
\text { caso, } 2017 .\end{array}$ & - & $\begin{array}{l}\text { Descrever os } \\
\text { principais sintomas e } \\
\text { tratamentos variados } \\
\text { usados para melhorar } \\
\text { a qualidade de vida } \\
\text { de pessoas com } \\
\text { esclerose múltipla } \\
\text { (EM), que necessita } \\
\text { de cuidados } \\
\text { paliativos. }\end{array}$ & $\begin{array}{l}\text { É necessário melhorar a qualidade } \\
\text { dos profissionais e serviços de } \\
\text { cuidados paliativos, permitindo } \\
\text { acesso adequado aos pacientes, por } \\
\text { tudo que a doença representa. }\end{array}$ \\
\hline
\end{tabular}


Tabela 3: Principais aspectos relacionados aos Cuidados Paliativos no manejo de pacientes com Mieloma múltiplo no artigo.

\begin{tabular}{|c|c|c|c|c|}
\hline Título & $\begin{array}{l}\text { Ano e } \\
\text { desenho de } \\
\text { estudo }\end{array}$ & Amostra & Objetivos & Resultados \\
\hline $\begin{array}{l}\text { Mechanisms } \\
\text { and treatment } \\
\text { of bone pain in } \\
\text { multiple } \\
\text { myeloma. }\end{array}$ & $\begin{array}{l}\text { Revisão de } \\
\text { literatura, } \\
2019 .\end{array}$ & - & $\begin{array}{l}\text { Abordar o manejo da } \\
\text { dor nos pacientes } \\
\text { com Mieloma } \\
\text { Múltiplo, com a } \\
\text { manifestação mais } \\
\text { frequente sendo a dor } \\
\text { óssea. }\end{array}$ & $\begin{array}{l}\text { Dor óssea é causada por associação } \\
\text { de vários mecanismos, contudo, o } \\
\text { derivado da dor óssea neuropática } \\
\text { ainda não é totalmente elucidado. } \\
\text { Com base nos diversos } \\
\text { mecanismos propostos, o manejo } \\
\text { da dor nesses pacientes é revisto ao } \\
\text { longo do estudo. Um dos agentes } \\
\text { propostos para controle da dor é a } \\
\text { Cannabis medicinal. }\end{array}$ \\
\hline
\end{tabular}

Tabela 4: Artigos relacionando dor crônica, dor e caquexia relacionada ao câncer, demência e doença de Alzheimer e doenças crônicas em Cuidados Paliativos ao uso da Cannabis Medicinal

\begin{tabular}{lllll}
\hline Título & $\begin{array}{l}\text { Ano e } \\
\text { desenho de } \\
\text { estudo }\end{array}$ & Amostra & Objetivos & Resultados \\
\hline
\end{tabular}

\begin{tabular}{|c|c|c|c|}
\hline $\begin{array}{l}\text { Cannabis for } \\
\text { Symptom } \\
\text { Management } \\
\text { in Older } \\
\text { Adults. }\end{array}$ & $\begin{array}{l}\text { Revisão da } \\
\text { literatura, } \\
2020 .\end{array}$ & $\begin{array}{l}8 \text { Ensaios } \\
\text { Clínicos } \\
\text { Randomizados. }\end{array}$ & $\begin{array}{l}\text { Apresentar evidências em } \\
\text { relação à eficácia e } \\
\text { segurança da terapia com } \\
\text { Cannabis para manejo de } \\
\text { sintomas de pacientes sob } \\
\text { Cuidados Paliativos, sendo } \\
\text { estes: dor crônica, dor e } \\
\text { caquexia relacionada ao } \\
\text { câncer, demência e doença } \\
\text { de Alzheimer. }\end{array}$ \\
\hline
\end{tabular}

Em relação à dor crônica, três estudos demonstraram pelo menos redução de $30 \%$ na dor. Um estudo demonstrou queda significativa na dor e um estudo, de evidência mista, não demonstrou diferenças significativas na redução da dor. Foram usados THC ou CDB, via oral, sublingual, vaporizado, fumado e inalado e observados efeitos colaterais leves a moderados ou ausência de efeitos colaterais. 


\begin{tabular}{|c|c|c|c|c|}
\hline Título & $\begin{array}{l}\text { Ano e } \\
\text { desenho de } \\
\text { estudo }\end{array}$ & Amostra & Objetivos & Resultados \\
\hline
\end{tabular}

Tetrahydroca Estudo nnabinol and transversal, Cannabidiol 2020. use in an outpatient palliative medicine population.
58 pacientes com doenças crônicas em cuidados paliativos.
Descrever padrões de uso de THC e CBD no Estado da Flórida após a aprovação da lei que legalizou o uso da Cannabis medicinal $\mathrm{e}$ relatou os benefícios percebidos e os efeitos colaterais.

Demonstrar os procedimentos dos cuidados paliativos no controle dos sintomas, definindo os sintomas sobre os quais os canabinóides poderiam agir.
Dos 58 pacientes, 14 referiram usar THC. Foi relatado melhora na dor. E destes 14, $71 \%$ começaram a usar o canabinóide na forma vaporizada, após o diagnóstico. Também 14 pacientes dos 58, relataram usar o $\mathrm{CBD}$, principalmente tópico. Nenhum destes 14 haviam usado CBD antes do diagnóstico. Ambos referiram mínimos efeitos colaterais.

Apesar de estudos anteriores promissores, três estudos recentes de Fase 3 de nabiximols em pessoas com câncer avançado possuindo dor, não tiveram alívio da dor, já que a otimização de opioides não demonstrou benefício na média auto-relatada das escalas de classificação numérica para dor. 
Tabela 5: Resumo do artigo sobre os aspectos legais e de custos do uso da Cannabis na Europa para o manejo de dor crônica e sintomas de pacientes em Cuidados Paliativos

\begin{tabular}{|c|c|c|c|c|}
\hline Título & $\begin{array}{l}\text { Ano e desenho } \\
\text { de estudo }\end{array}$ & Amostra & Objetivos & Resultados \\
\hline $\begin{array}{l}\text { Availability } \\
\text { and approval } \\
\text { of } \\
\text { Cannabis-bas } \\
\text { ed medicines } \\
\text { for chronic } \\
\text { pain } \\
\text { management } \\
\text { and } \\
\text { palliative/sup } \\
\text { portive care } \\
\text { in Europe: A } \\
\text { survey of the } \\
\text { status in the } \\
\text { chapters of } \\
\text { the European } \\
\text { Pain } \\
\text { Federation. }\end{array}$ & $\begin{array}{l}\text { Estudo } \\
\text { qualitativo, } \\
2017 .\end{array}$ & $\begin{array}{l}\text { Foram } \\
\text { contatados } 37 \\
\text { países da } \\
\text { Federação } \\
\text { Europeia da } \\
\text { Dor (EFIC), } \\
\text { representados } \\
\text { por } \\
\text { conselheiros. }\end{array}$ & $\begin{array}{l}\text { Avaliar o status de } \\
\text { aprovação da Cannabis } \\
\text { medicinal no manejo da } \\
\text { dor crônica (com } \\
\text { disponibilidade de um } \\
\text { documento de alguma } \\
\text { associação médica } \\
\text { nacional) e controle dos } \\
\text { sintomas em CP ou em } \\
\text { tratamento de suporte e } \\
\text { a cobertura dos custos. }\end{array}$ & $\begin{array}{l}21 \text { países utilizam a combinação } \\
\text { de THC e de CBD na forma de } \\
\text { Spray mucoso (Nabiximol) no } \\
\text { tratamento da espasticidade na } \\
\text { esclerose múltipla refratária ao } \\
\text { tratamento convencional. O } \\
\text { THC é aprovado em } 3 \text { países } \\
\text { para náuseas e vômitos em } \\
\text { pacientes oncológicos ou sob } \\
\text { cuidados paliativos e na Irlanda } \\
\text { é aprovado para estimulação do } \\
\text { apetite em pacientes com HIV. } \\
\text { Na Alemanha pode ser prescrito } \\
\text { para qualquer tipo de dor } \\
\text { crônica e para qualquer } \\
\text { condição de cuidado paliativo. } \\
\text { O nabilone, análogo do THC, é } \\
\text { aprovado na forma de } \\
\text { comprimido para náuseas e } \\
\text { vômitos refratários ao } \\
\text { tratamento convencional em } \\
\text { pacientes sob quimioterapia. Na } \\
\text { Eslovênia, estão disponíveis } \\
\text { dronabinol sintético e análogos } \\
\text { do canabidiol para programas de } \\
\text { uso excepcional sem reembolso, } \\
\text { exceto em casos especiais a } \\
\text { pedido individual. Até } 14 \text { tipos } \\
\text { de flores de Cannabis medicinal } \\
\text { estão disponíveis em } \\
\text { concentrações variadas de THC } \\
\text { (1\% a } 22 \% \text { e CBD ( } 0,05 \% \text { e } \\
9 \% \text { ). Oito países europeus têm } \\
\text { um programa de uso } \\
\text { excepcional para permitir acesso } \\
\text { a flores de Cannabis para o } \\
\text { tratamento de uma gama de } \\
\text { condições médicas. Já o acesso } \\
\text { expandido se dá em Israel e } 5 \\
\text { países europeus. }\end{array}$ \\
\hline
\end{tabular}




\section{DISCUSSÃO}

Dentre os resultados obtidos, houve controvérsias quanto ao uso da Cannabis medicinal em pacientes de cuidados paliativos. Alguns estudos que abordaram pacientes oncológicos, demonstraram resultados animadores na redução de dor, alívio de náuseas e vômitos e melhora na qualidade de vida. No entanto, efeitos colaterais como tontura, xerostomia, aumento de apetite, sonolência e efeito psicoativo foram observados ${ }^{7,8,9}$. Outros artigos têm mostrado benefícios no uso da Cannabis em cuidados paliativos de pacientes com mieloma múltiplo, com melhora da dor e melhora da dor na esclerose múltipla ${ }^{17,18}$. Alguns autores não recomendaram o uso da planta em idosos pelo fato de haver dados insuficientes na determinação de eficácia e segurança quanto à dosagem, via de administração e efeitos colaterais. A Federação Europeia da Dor (EFIC) mostrou diferenças significativas no que tange à legalização e prescrição da Cannabis entre os países Europeus. Ainda, revelou preocupações em relação à cobertura dos custos pelos seguros de saúde e sistemas estaduais de previdência social ${ }^{14}$.

\section{CONCLUSÃO}

Embora existam evidências que apoiam o uso de Cannabis medicinal em cuidados paliativos, principalmente para pacientes oncológicos, há necessidade de mais estudos com amostras maiores, determinação do tempo de tratamento, avaliação dos efeitos do tratamento de curta e de longa duração, definição de formulações e doses, critérios para a seleção, orientação e acompanhamento dos pacientes, principalmente na população idosa, além de debates quanto à dificuldade de se obter os produtos farmacêuticos derivados da Cannabis medicinal. Outro aspecto preocupante refere-se ao conceito errado, principalmente da mídia, que confunde a droga ilegal com o produto licenciado como medicamento, gerando desconfianças da população com relação ao seu uso. Por fim, é preciso capacitar profissionais e pacientes para superar os estigmas e medos em torno do uso da planta.

\section{DESCRITORES}

Dor, Cuidados Paliativos, Maconha Medicinal.

\section{REFERÊNCIAS}

1. Gomes, ALZ; Othero, MB. Cuidados paliativos. Estudos Avançados. [S.L.], v. 30, n. 88, p. 155-166, dez. 2016. Fap UNIFESP (SciELO). 
2. De Santana, JM; Perissinotti, DMN; de Oliveira Junior, JO; Correia, LMF; Oliveira, CM de; Fonseca, PRB da. Definition of pain revised after four decades. Brazilian Journal Of Pain, [S.L.], v. 3, n. 3, p. 197-198, 21 set. 2020. GN1 Genesis Network.

3. Ministério da Saúde (Brasil), Secretaria de Atenção Especializada à Saúde/SAES. Manual de Cuidados Paliativos. São Paulo, 2020. 175p

4. Levy C, Galenbeck E, Magid K. Cannabis for Symptom Management in Older Adults. Med Clin North Am. 2020 May;104(3):471-489.

5. Highet BH, Lesser ER, Johnson PW, Kaur JS. Tetrahydrocannabinol and Cannabidiol Use in an Outpatient Palliative Medicine Population. Am J Hosp Palliat Care. 2020 Aug;37(8):589-593.

6. Waissengrin B, Urban D, Leshem Y, Garty M, Wolf I. Patterns of use of medical cannabis among Israeli cancer patients: a single institution experience. J Pain Symptom Manage. 2015 Feb; 49(2): 223-30.

7. Singh V, Zarrabi AJ, Curseen KA, Sniecinski R, Welsh JW, McKenzie-Brown AM, Baer W, Gillespie TW. Concerns of Patients With Cancer on Accessing Cannabis Products in a State With Restrictive Medical Marijuana Laws: A Survey Study. J Oncol Pract. 2019 Oct;15(10): 531-538.

8. Davies MP, Fingas S, Chantry A. Mechanisms and treatment of bone pain in multiple myeloma. Curr Opin Support Palliat Care. 2019 Dec;13(4): 408-416.

9. Costello J. Preserving the independence of people living with multiple sclerosis towards the end of life. Int J Palliat Nurs. 2017 Oct 2;23(10):474-483.

10. Maida V. Medical Cannabis in the Palliation of Malignant Wounds-A Case Report. J Pain Symptom Manage. 2017;53(1):e4-e6.

11. Clark CS. Medical Cannabis: The Oncology Nurse's Role in Patient Education About the Effects of Marijuana on Cancer Palliation. Clin J Oncol Nurs. 2018 Feb 1;22(1):E1-E6.

12. Ritter JM, et al. Rang \& Dale Farmacologia. 9th ed. Rio de Janeiro: GEM | Grupo Editorial Nacional; 2020. 808 p.

13. Bar-Lev Schleider L, Mechoulam R, Lederman V, Hilou M, Lencovsky O, Betzalel O, Shbiro L, Novack V. Prospective analysis of safety and efficacy of medical cannabis in large unselected population of patients with cancer. Eur J Intern Med. 2018 Mar;49:37-43.

14. Krcevski-Skvarc N, Wells C, Häuser W. Availability and approval of cannabis-based medicines for chronic pain management and palliative/supportive care in Europe: A survey of the status in the chapters of the European Pain Federation. Eur J Pain. 2018 Mar;22(3):440-454. 
15. BRASIL. Lei no 11343, de 23 de Agosto de 2006. Prescreve medidas para prevenção do uso indevido, atenção e reinserção social de usuários e dependentes de drogas; estabelece normas para repressão à produção não autorizada e ao tráfico ilícito de drogas e define crimes. Brasília, DF: Poder executivo, 2006.

16. Elias, JSJ; Oliveira, BMJF de; Barbosa, MNR. Anseios e devaneios: a memória social envolta ao progresso de legalização da maconha para fins medicinais no Brasil. Perspectivas em Ciência da Informação, [S.L.], v. 25, n. 3, p. 63-81, jul. 2020. FapUNIFESP (SciELO).

17. Turgeman I, Bar-Sela G. Cannabis for cancer - illusion or the tip of an iceberg: a review of the evidence for the use of Cannabis and synthetic cannabinoids in oncology. Expert Opin Investig Drugs. 2019 Mar;28(3):285-296

18. Agar M. Medicinal cannabinoids in palliative care. Br J Clin Pharmacol. 2018 Nov; 84(11): 2491-2494. 